\title{
How Strategic Priorities Are Reflected in Features of Strategic Performance Measurement System?
}

\section{Ladislav Siska}

\author{
Masaryk University \\ Lipova 41 ${ }^{a}$, CZ-60200, Brno, Czech Republic \\ E-mail. ladislav.siska@econ.muni.cz \\ cross $^{\text {ref }}$ http://dx.doi.org/10.5755/j01.ee.29.5.17463
}

\begin{abstract}
Strategic Performance Measurement Systems (SPMSs) are designed to present integrated information, which together with other controls in Management Control Systems (MCSs) helps managers to implement strategy properly and thus outperform the company's competitors. A wide range of potential factors impacting the design and use of SPMS and MCS has been studied by proponents of the contingency theory since the 1980s who soon found strategy to be one of the most dominant contingencies. But recent reviews of contingency theory provide mixed, sometimes even conflicting evidence, partly because of inconsistent definitions of MCS and SPMS, partly because of exploring contingencies in isolation from other context factors and components. This article addresses both of these challenges. Firstly, it introduces four distinctive features of SPMS and complements them with often neglected "Beliefs" and "Boundaries" controls from the influential MCS framework "Levers of Control" devised by Simons (1995). Secondly, the resulting MCS concept is tested by PLS-SEM whether or not it is influenced by contingency factors of size, industry and especially by two opposing Porter's generic strategic priorities - differentiation and/or cost-leadership (low prices). Surprisingly, only the former is found to be positively connected to the features of SPMS, however, the link is not direct but mediated by improvements in Boundaries and Beliefs. So the study broadens current knowledge on antecedents of SPMSs, that are applied in the medium-sized and large companies. At the same time, the study urges managers trying to implement differentiation strategy not only to establish the SPMS with all analyzed features, but concurrently to promote values and other belief controls as well as to set organizational rules and boundaries. In other words, the implementation of differentiation strategy has to be accompanied by establishment of the MCS incl. Beliefs and Boundaries, not just SPMS. Contrary to this implication, in case of low-price strategy, the detailed analysis proves that Belief and Boundary components of MCS are not very important tools for achieving cost-leadership.
\end{abstract}

Keywords: Contingency Theory; Differentiation Strategy; Cost-leadership Strategy; Performance Measurement; Performance Measurement Systems; Management Control; Levers of Control.

\section{Introduction}

At the first glance, mapping the relation between strategic priorities and strategic performance system (SPMS) looks like very simple task. At least, the same adjective at the beginning of both concepts evokes that there has to be some association between them. In general it holds true, but the quest for a detailed answer makes the task more demanding. Complications start with the fact that there are at least three parallel streams in academic accounting literature covering similar topics at the same time. The first literature stream highlights the instrumental view of strategic management accounting (SMA) investigated by Cadez \& Guilding (2008, 2012), Guilding et al. (2000), Langfield- Smith (2008), Pavlatos \& Kostakis (2015) or Ross \& Kovachev (2009). The second literature stream puts emphasis on measures and on the process of measurement. Topics cover the importance of nonfinancial measures (Eccles, 1991; Franco- Santos et al., 2007; Ittner \& Larcker, 1998, 2003; S.A. Melnyk, Stewart, \& Swink, 2004; Neely, Gregory \& Platts, 1995), comprehensive frameworks like balanced scorecard (Kaplan \& Norton, 1992, 1996), tableaux de bord (Epstein \& Manzoni, 1998), or Performance Prism (Neely et al., 2000). The third massive body of literature deals with the previously mentioned broader concept of management control system (MCS) preferred by authors such as Bedford \& Malmi (2015), Chenhall (2006), Malmi \& Brown (2008), Merchant \& Otley (2006), Simons (1995) or Tessier \& Otley (2012).

There are no strict demarcation lines between the literature streams described above. On the contrary, many authors (Franco- Santos et al., 2007; Garengo \& Bititci, 2007; Melnyk et al., 2014) have discussed the overlaps and tried to offer distinctive definitions. Some frameworks and classifications (Ferreira \& Otley, 2009; Franco-Santos et al., 2012; Speckbacher et al., 2003) were suggested too. The evident decline of interest in SMA that has been documented since its 'glory decade' of the 1990s (Langfield- Smith, 2008; Nixon \& Burns, 2012) justifies the omission of SMA in this study.

The overlaps of the three discussed literature streams can be exemplified through the popular Balanced Scorecard (BSC) which emerges in all of them. Firstly, BSC is considered to be one of the most typical examples of SMA tools (Langfield- Smith, 2008). BSC combines financial and non-financial measures and its authors themselves categorized BSC as a strategic performance measurement system (SPMS), i.e. a subset of PMS. Later they came up 
with another supplementary tool - strategy maps (Kaplan \& Norton, 2004) which connect performance measurement and strategic management. The intended purpose of strategy maps lies in helping managers with linking the strategic objectives, hence improving the description and consequent implementation of strategy. Finally, it is possible to view $\mathrm{BSC}$ as a fundamental component of the MCS of the whole company. In other words, BSC presents one of the most important controls, which integrates strategic plans and operational execution as demonstrated in Kaplan and Norton (2008).

The BSC example sheds light on the intertwined nature of SMA, SPMS and MCS. Innumerable case studies of BSC implementation and different structure of BSC perspectives applied in these cases demonstrate that there is no universal solution that fits all possible situations and purposes. This resonates with the basic idea of contingency research that no single SPMS or MCS is optimal in all situations and that the choices depend on several situational (or contingency) factors. In his overview of the contingency-based literature, Chenhall $(2003,2006)$ identified six groups of contingency factors: (1) the external environment, (2) technology, (3) structure, (4) size, (5) strategy, and (6) culture. Recent studies (Bedford \& Malmi, 2015; Bisbe \& Malagueño, 2012; Chenhall, 2005; Davila et al., 2015; Garengo \& Bititci, 2007; Henri, 2006a, 2006b; Koufteros et al., 2014; Langfield-Smith, 2006; Taylor \& Taylor, 2014; Widener, 2007) addressed many of the contingency factors in detail. Otley (2016) concludes in his review covering the past forty years that contingency theory is a success story, but at the same time he points out the shortcomings of the analyzed studies related to the "lack of attention paid to the conceptualization of the overall MCS" and the fact that "elements of an overall MCS have been studied ... in isolation from the context of the other elements which surround them." (p. 55)

The aim of this study is to clarify the relationships between dominant contingency factors - especially strategy which was found the most important by Langfield-Smith (2006) - on the one hand and SPMS on the other by embedding SPMS into the entire MCS of a company. In other words, this study presumes that it is the context and other components of MCS that predetermine the choice of and relationships among metrics included in the SPMS. This fact is often omitted by just focusing on SPMS or by simple identification of SPMS with MCS.

The objective of the study is to test through PLS structural equation modelling whether the hypothesized impact of strategic choice (alongside contingency factors of size and industry) on four distinctive features of SPMS is mediated by the decision about the other characteristics of MCS, namely belief and boundary systems.

This study responds to the mentioned critique of insufficient conceptualization by elaborating the main features of SPMS and verifying empirically their relations to the other main controls from the overall MCS.. Consequently, three contingency factors found dominant in the studies carried out in developed countries are regressed on the analyzed controls and SPMS features. That brings novel findings whether situation in the Czech Republic is different from the developed world as might be expected based on Paladi and Fenies (2016) who brought to attention the differences in management accounting research in Central and Eastern European countries.

The remainder of the article is organized as follows. Firstly, main concepts and hypothesized links among them have been developed. Secondly, the methodology of the survey and results are introduced. The findings are then compared with similar studies in the Discussion section. Finally, the main outcomes are summarized in the Conclusions section.

\section{Theory, Concepts and Hypotheses Development}

The theoretical model applied in this study is illustrated in Figure 1 where the main concepts are depicted in bold. The central SPMS concept is in the grey rectangle and consists of its four distinctive features discussed below. The reason why the grey rectangle is inserted in a bigger rectangle is that SPMS constitutes just one of a number of components which are part of the overall MCS. Finally, there are depicted four contingency factors selected for analysis and black arrows of tested relations expressed as hypotheses below.

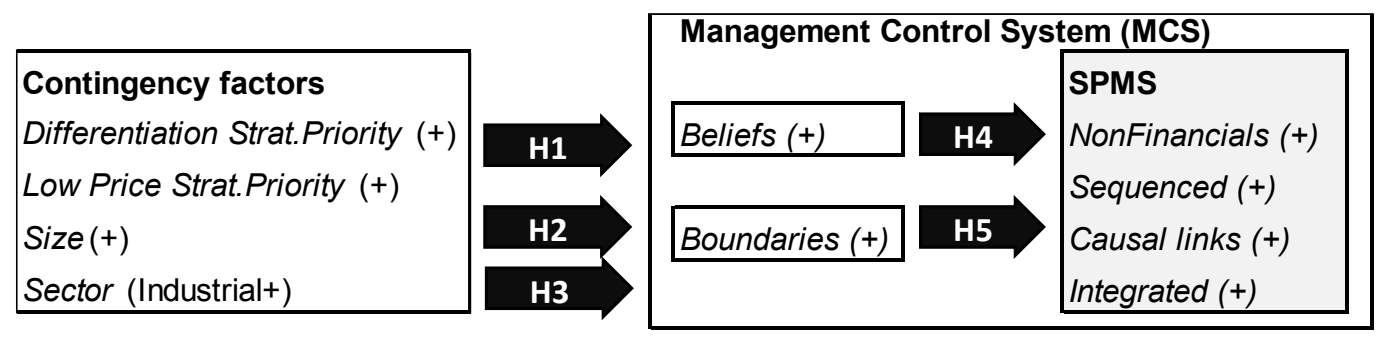

Figure 1. The Theoretical Model

The concept of SPMS in this study draws on Gimbert et al. (2010) who define SPMS as a strategy focused subset of overall PMS and PMS as "concise sets of metrics (financial and/or non-financial) that support the decision-making processes of an organization by gathering, processing and analyzing quantified information about its performance, and presenting it in the form of a succinct overview." (p. 493)
Instances of well-established SPMSs include BSC, tableauxde-bord, Performance Pyramid, or Performance Prisms. There is a general consensus (Bhimani \& Langfield-Smith, 2007; Chenhall, 2005; Franco-Santos et al., 2012; Kaplan \& Norton, 1992) that not only financial, but also non-financial metrics should be included in the SPMS. In addition, the objectives (e.g. modeled in strategy maps) and measures in 
SPMS should form cause-effect chains (Ittner \& Larcker, 2003; Speckbacher et al., 2003). The next distinctive feature of SPMS is that it provides a sequence of goals-metricstargets-action plans/strategic initiatives (Gimbert et al., 2010; Kaplan \& Norton, 2008; Speckbacher et al., 2003). Finally, there is the requirement of integration of a long-term strategy and operational goals (Chenhall, 2005; Gimbert et al., 2010; Kaplan \& Norton, 1996).

SPMS characterized by its four distinctive features belongs to the broader category of MCS. According to Malmi and Brown (2008), management controls include "all the devices and systems managers use to ensure that the behaviors and decisions of their employees are consistent with the organization's objectives and strategies." (p. 290) They distinguish (1) administrative, (2) planning, (3) cybernetic, (4) cultural controls and (5) rewards and compensations as the main components of their MCS package. In a simplified way, the components (2) and (3) can be identified with SPMS.

However, the presented MCS package offered by Malmi and Brown (2008) is just one possible example, in fact, there is no agreed structure or content of MCS. Strauß and Zecher (2013) identified three most influential conceptualizations of MCS based on survey among accounting researchers. One of them is Simons' Levers of Control framework. It builds on the idea of opposing forces that, according to Simons (1995), manage tensions "between freedom and constraint, between empowerment and accountability, between top-down direction and bottom-up creativity, between experimentation and efficiency" (p. 4). Simons identifies four levers of control. Of the four levers, two are defined as positive (belief systems and interactive control systems) and two are defined as negative (boundary systems and diagnostic control systems). Otley (2016) observes that the distinction between diagnostic and interactive uses achieved great popularity in the contingency work. Eventually, in Czechia they have already been analyzed by (Siska, 2016). That is why the less well-researched levers of beliefs and boundaries were selected for analysis in this study.

Belief systems were specified by Simons (1995) as "the explicit set of organizational definitions that senior managers communicate formally and reinforce systematically to provide basic values, purpose, and direction for the organization." (p. 34) Beliefs are positive definitions of future behavior of the company, as opposed to boundaries, which "delineate the acceptable domain of strategic activity for organizational participants." (Simons, 1995, p. 39) In his later publication, Simons (2010) explains the role of strategic boundaries: "Every strategy carries the risk that an individual's actions will push the business off course. The risk intensifies when managers feel pressure to hit growth and profit targets. There are two ways to control such risk: You can tell people what to do, or you can tell them what not to do." In other words, the boundaries may be detailed prescriptions and pre-action reviews, or bans and definitions of employees' off-limit behavior.

There is only limited knowledge about the relationships between levers of control and SPMS, which is restrained to the inclusion of non-financial metrics into SPMS. Grafton, Lillis and Widener (2010) found positive association between performance measures applied in SPMS and feedback and feed-forward control uses, which are equivalent to diagnostic and interactive use. Bedford and Malmi (2015, p. 12) report the bivariate correlation of 0.44 between the diversity of MCS (extent of non-financials in MCS) and belief systems, 0.38 between the diversity and boundary systems. Based on these findings, the following hypotheses were derived:

(H4) The more a company articulates its core values and beliefs, the more distinctive features of its SPMS it reports.

(H5) The more explicitly a company sets the bans, rules and similar boundary controls, the more distinctive features of its SPMS it reports.

As far as the third important concept in Figure 1 is concerned, literature offers myriads of contingency factors. This study focuses above all on strategy. The reason is, that Langfield-Smith (2006) found strategy to be one of the dominant contingency factors in her review of quantitative studies. At the same time, she identified three typologies of strategies applied in the contingency studies: (1) cost leadership-differentiation, (2) build-hold-harvest, (3) prospector-defender. This study uses the first typology defined by Porter (1980) and presumes that more explicitly pronounced strategic priorities are reflected in the stronger emphasis on all components of MCS. This hypothesis draws on Magretta (2013), who describes a common strategic mistake known as getting stuck in the middle: "This happens when a company tries to be all things to all customers and is outflanked by cost leaders on one side, who meet just enough of their customer's needs, and by differentiators on the other side, who do a better job of satisfying customers who want more (of some particular attribute they value).“ (p. 114) In other words, companies stuck in the middle strategically are expected to be similarly stuck in the middle as far as MCS and SPMS is concerned and deploying just average components of MCS:

(H1) Perceived higher strategic priority of either differentiation, or low-price reflects in higher emphasis on belief controls, boundary controls and/or all features of SPMS respectively.

All reviews of MCS contingencies (Chenhall, 2006; Otley, 2016) mention the size and industry as important contingency factors. This is not surprising, because the strong associations between size and adoption of MCS or SPMS was found in many studies (Cadez \& Guilding, 2008; Garengo \& Bititci, 2007; Speckbacher et al., 2003; Taylor \& Taylor, 2014). It has been shown that MCSs tend to be more specialized and sophisticated in larger firms, possibly because larger firms can more easily afford to support such systems. In addition, (Speckbacher et al., 2003) reports: "We found that firms belonging to the consumer \& retail industry are associated with a significantly lower usage of BSC.” (p. 375) That is why the following hypotheses were formulated:

(H2) Larger companies put more pressure on belief controls, boundary controls and all features of SPMS.

(H3) Industrial companies use more enhanced controls in their MCS consisting of beliefs, boundaries and SPMS features.

\section{Methods}

The main method became a web-based empirical survey. The questions are presented below, together with the 
assessment of construct validity. Potential respondents recruited from the population comprising 8,687 marketoriented companies (except agriculture) domiciled in the Czech Republic. The second restraining condition for selection of responding companies was more than 50 fulltime employees (FTEs). The stratified sample of 2,076 companies (stratas based on sector and county) was addressed in November with two follow-ups (the $2^{\text {nd }}$ postal) in December 2016. The structure of the final sample of 156 useable questionnaires is shown in Table 1.

Response rate amounted to approximately 7 percent. To exclude a risk of non-response bias, quarters of early and late respondents were compared through Mann-Whitney U tests. No significant differences between were found.

Table 1

Data Sample Characteristics

\begin{tabular}{|c|c|c|c|c|c|c|c|}
\hline Managerial rank & Count & Function & Count & Sector & Count & Size & Count \\
\hline Top manager or owner & 77 & CEO or owner & 38 & Industrial & 83 & Medium-sized (50-249 FTEs) & 80 \\
\hline Middle manager & 33 & Finance & 42 & Trade & 18 & Large (>250 FTEs) & 76 \\
\hline Lower (first-line) manager & 16 & Marketing & 21 & Services & 55 & & \\
\hline Non-managers & 26 & Operations & 18 & & & & \\
\hline \multirow[t]{2}{*}{$\mathrm{n} / \mathrm{a}$} & 4 & Procurement & 8 & & & & \\
\hline & & Other & 29 & & & & \\
\hline Total & 156 & Total & 156 & Total & 156 & Total & 156 \\
\hline
\end{tabular}

Due to relatively low response rate, the second wave of data collection was organized with the help of students of Masaryk University in Autumn 2017. In this case, there was no frame for sampling. Students contacted their acquaintances, friends and family members owning or working for the companies fulfilling criteria for potential respondents of the previous survey. The resulting convenience sample comprised 110 companies. It is referred to as control sample below and all the procedures were applied to it as well even though this article focuses primarily on data from survey.

All obtained data was processed with the use of structural equation modelling (SEM), which is promoted by Chenhall (2003) and Smith \& Langfield-Smith (2004). Considering the characteristics of the data sample, partial least square (PLS) was preferred to covariance-based (CB) approach to SEM. The statistical software SmartPLS v. 3.2.6 (Ringle et al., 2015) was used for data processing. In all procedures, the mean replacement of the cases with missing values was selected to preserve as much data as possible, but missings did not present a big problem (less than 5 percent missing rate in questions altogether).

Skewness and kurtosis measures deviated from the interval $[-1,1]$ only in the case of variable (q2), but the formal Lilliefors Corrected Kolmogorov-Smirnov test signaled the non-normal distribution of most variables. This and the relatively small size of the sample led to the use of PLS approach to SEM and rather than the traditional covariancebased SEM. The third reason for PLS-SEM application is given by Lee et al. (2011, p. 314): "Thanks to the explicit estimation of the latent variables, no identification problem arises in the PLS approach." That was why sometimes even single-item constructs were created.

To the measurement model, all constructs entered as reflective, because individual questions from the questionnaire tried to ask about the same aspect of the same construct. To assess the internal reliability, Cronbach's alphas were calculated. However, Cronbach's alpha assumes that all indicators are equally reliable. Therefore, the main criterion for reliability assessment became Composite Reliability, which takes into account the different outer loadings and according to Hair et al. (2014) "values between 0.70 and 0.90 (0.95) can be regarded as satisfactory" (p. 102). These criteria were met - logically except for single-item constructs where they equal to 1 - as shown in Table 2 .

Reliability is a necessary but not sufficient condition for validity. To guarantee that a construct is measured accurately, the convergent validity had to be assessed, i.e. the extent to which an item correlates positively with alternative indicator of the same construct. The main criteria were the outer loadings greater than 0.7 based on Lee et al. (2011) and Average Variance Explained (AVE), which is an equivalent of the communality of a construct. AVE value of 0.50 or higher indicates that, on average, the construct explains more than half of the variance of its items. The mentioned AVE measures for each construct and the outer loadings of each indicator used are depicted in bold in Table 2. The values show a proper fulfilment of conditions of convergent validity, except the constructs Boundaries with bordering AVE and SPMS NonFin and Beliefs with outer loadings lower than 0.7, but still higher than the satisfactory level of 0.6. That is why the convergent validity was assessed as satisfactory.

Discriminant validity, i.e. the extent to which a construct is truly distinct from other constructs, was tested by the rule that loadings on the construct should be higher than all its cross loadings with other constructs. Data in Table 2 confirm the fulfilment of this rule. More formal Fornell-Larcker criterion indicated discriminant validity of the constructs, as well.

Rigdon (2012) states that PLS-SEM does not allow for testing the overall goodness of the model fit in a CB-SEM sense. The key criteria for assessing the structural model in PLS-SEM are the significance of the path coefficients and the level of the explained variance of endogenous constructs measured through the coefficients of determination $\left(\mathrm{R}^{2}\right.$ values). To calculate the significance of the path coefficients, Bias-Corrected and Accelerated Bootstrapping with 5000 subsamples was applied. The $\mathrm{R}^{2}$ represents the proportion of the variance of the dependent (endogenous) variable explained by the independent variables, similarly to the 
multiple regression. Lee et al. (2011) based on Falk and Miller (1992) recommend that the $\mathrm{R}^{2}$ for endogenous variables should be greater than 0.10 . Hair et al. (2014, p. 21) is more accurate and states that to detect minimum $\mathrm{R}^{2}$ values of 0.10 in any of the endogenous constructs in the structural model for significance levels of $5 \%$, assuming the commonly used level of statistical power of $80 \%$ and no more than 3 arrows pointing at one construct, at least 124 observations are needed. Thus, with 156 cases in this study, the $0.10 \mathrm{R}^{2}$ values should be assessable. Finally, VIFs not exceeding 2.06 did not indicate any problems with multicollinearity in the resulting model which is presented here.

The strength of relationship coefficients (e.g. correlation coefficients, standardized path coefficients) was interpreted based on De Vaus (2002, p. 259) as very small (0.01-0.09), small, low (0.10-0.29), medium (0.30-0.49), large, high (0.50-0.69).

Table 2

Internal Consistency and Validity of the Analyzed Constructs

\begin{tabular}{|c|c|c|c|c|c|c|c|c|}
\hline Construct: & Beliefs & Boundaries & $\begin{array}{c}\text { SPMS } \\
\text { NonFin }\end{array}$ & $\begin{array}{l}\text { SPMS } \\
\text { causal }\end{array}$ & $\begin{array}{c}\text { SPMS } \\
\text { integrated }\end{array}$ & $\begin{array}{c}\text { SPMS } \\
\text { sequenced }\end{array}$ & $\begin{array}{c}\text { StratPrior } \\
\text { Different }\end{array}$ & $\begin{array}{l}\text { StratPrior } \\
\text { LowPrice }\end{array}$ \\
\hline Cronbach's Alpha & 0.703 & 0.744 & 0.754 & 1.000 & 0.741 & 0.835 & 0.623 & 1.000 \\
\hline Composite Reliability & 0.818 & 0.827 & 0.842 & 1.000 & 0.885 & 0.924 & 0.837 & 1.000 \\
\hline AVE & 0.534 & 0.490 & 0.574 & 1.000 & 0.794 & 0.858 & 0.721 & 1.000 \\
\hline StratPrior Low-Price (q1) & -0.212 & -0.234 & 0.003 & -0.074 & -0.094 & -0.182 & 0.054 & 1.000 \\
\hline StratPrior Different (q2) & 0.270 & 0.263 & 0.122 & 0.008 & 0.096 & -0.050 & 0.904 & -0.022 \\
\hline StratPrior Different (q3) & 0.104 & 0.251 & 0.217 & 0.027 & 0.054 & 0.003 & 0.791 & 0.143 \\
\hline SPMS NonFin (q4) & 0.068 & 0.177 & 0.688 & 0.219 & 0.240 & 0.195 & 0.119 & 0.059 \\
\hline SPMS NonFin (q5) & 0.313 & 0.206 & 0.666 & 0.076 & 0.161 & 0.117 & 0.224 & -0.017 \\
\hline SPMS NonFin (q6) & 0.196 & 0.261 & 0.817 & 0.157 & 0.198 & 0.214 & 0.107 & 0.024 \\
\hline SPMS NonFin (q7) & 0.245 & 0.298 & 0.843 & 0.307 & 0.323 & 0.261 & 0.147 & -0.043 \\
\hline SPMS sequenced (q8) & 0.255 & 0.265 & 0.230 & 0.494 & 0.674 & 0.919 & -0.050 & -0.145 \\
\hline SPMS sequenced (q9) & 0.305 & 0.319 & 0.266 & 0.561 & 0.713 & 0.933 & -0.012 & -0.190 \\
\hline SPMS integrated (q10) & 0.262 & 0.293 & 0.249 & 0.728 & 0.897 & 0.656 & 0.078 & -0.041 \\
\hline SPMS integrated (q11) & 0.285 & 0.385 & 0.309 & 0.614 & 0.885 & 0.681 & 0.086 & -0.129 \\
\hline SPMS causal (q12) & 0.278 & 0.320 & 0.264 & 1.000 & 0.754 & 0.571 & 0.019 & -0.074 \\
\hline Boundaries (q13) & 0.518 & 0.733 & 0.473 & 0.291 & 0.309 & 0.220 & 0.209 & -0.158 \\
\hline Boundaries (q14) & 0.481 & 0.793 & 0.116 & 0.249 & 0.322 & 0.309 & 0.243 & -0.231 \\
\hline Boundaries (q15) & 0.325 & 0.636 & 0.070 & 0.250 & 0.296 & 0.153 & 0.161 & -0.103 \\
\hline Boundaries (q16) & 0.377 & 0.653 & 0.167 & 0.078 & 0.092 & 0.078 & 0.170 & -0.177 \\
\hline Boundaries (q17) & 0.445 & 0.673 & 0.176 & 0.207 & 0.265 & 0.300 & 0.257 & -0.145 \\
\hline Beliefs (q18) & 0.660 & 0.374 & 0.073 & 0.161 & 0.228 & 0.235 & 0.060 & -0.173 \\
\hline Beliefs (q19) & 0.824 & 0.549 & 0.259 & 0.262 & 0.208 & 0.230 & 0.139 & -0.128 \\
\hline Beliefs (q20) & 0.600 & 0.335 & 0.159 & 0.076 & 0.130 & 0.127 & 0.290 & -0.094 \\
\hline Beliefs (q21) & 0.813 & 0.536 & 0.258 & 0.271 & 0.308 & 0.277 & 0.210 & -0.215 \\
\hline
\end{tabular}

The constructs were measured using Likert-scale survey questions with an available range of 1-7.

Strategic priorities constructs followed the questions offered by Chenhall (2005). Respondents indicated the emphasis their company (in comparison with direct competitors) puts on the following strategic priorities: (q1) low prices of products/services, (q2) reliable promises of supplies of products/services, (q3) swift delivery of products/services.

SPMS Nonfinancials were inspired by Bedford and Malmi (2015) and Bedford et al. (2016). Respondents were asked whether their SPMS contains indicators from the following non-financial areas (dimensions, perspectives): (q4) customers e.g. market share, satisfaction, repeated purchases, (q5) employees e.g. satisfaction, turnover, (q6) innovation of product/service portfolio e.g. time of development, changes to portfolio, extent of functionality, (q7) company's development e.g. approach to goals, accumulation of knowledge, contacts.
The rest of SPMS features stemmed from questions devised by Gimbert et al. (2010) and Speckbacher et al. (2003). Respondents were asked to indicate to what extent they agree with the following statements: (q8) strategic objectives are measured in SPMS through performance indicators with target values, (q9) SPMS contains strategic objectives as well as strategic initiatives/action plans to achieve them, (q10) performance indicators and their target values are explicitly linked in SPMS with a long-term strategy of the company, (q11) links between strategic initiatives and functional areas are included in SPMS, (q12) strategic objectives measured in SPMS make up chains of causes and expected results.

Beliefs and Boundaries constructs drew on Bedford and Malmi (2015) and Widener (2007). Respondents indicated a level of their agreement with the following statements: (q13) rules and policies precisely specify the area for the search of new opportunities and experimenting, (q14) top management clearly communicates risks and activities that 
employees should avoid, (q15) sanctions will be imposed without compromise on everybody who takes part in banned risky operations, regardless of the results, (q16) top management communicates what strategic initiatives are not supported so that the company does not dissipate its focus, (q17) the company knows and monitors the main risks threatening its good reputation, (q18) core values, mission and direction of the company are codified, (q19) core values give employees a guide for the search of new opportunities, (q20) by selecting managers, theirs attitudes and values aligned to the company's are more important than technical competence, (q21) top management relies on the shared values in providing direction when faced with uncertainty.

Categorical variables Size and Sector were drawn from BizNode database. Companies employing 50-249 FTEs were considered medium-sized, with more FTEs large. Category of industrial companies included CZ-NACE sections "B - mining and quarrying" through manufacturing, utilities up to "F - Construction". Category service/trade comprises "G - wholesale and retail trade" and all service sectors. For testing the differences, PLS Multi-Group Analysis (PLS-MGA) with non-parametric significance test of group-specific results was used (Sarstedt et al., 2011). Before running PLS-MGA, its necessary condition was successfully tested by MICOM procedure, which found partial measurement invariance in both subgroups formed by splitting the whole sample by Size and Sector variables, respectively.

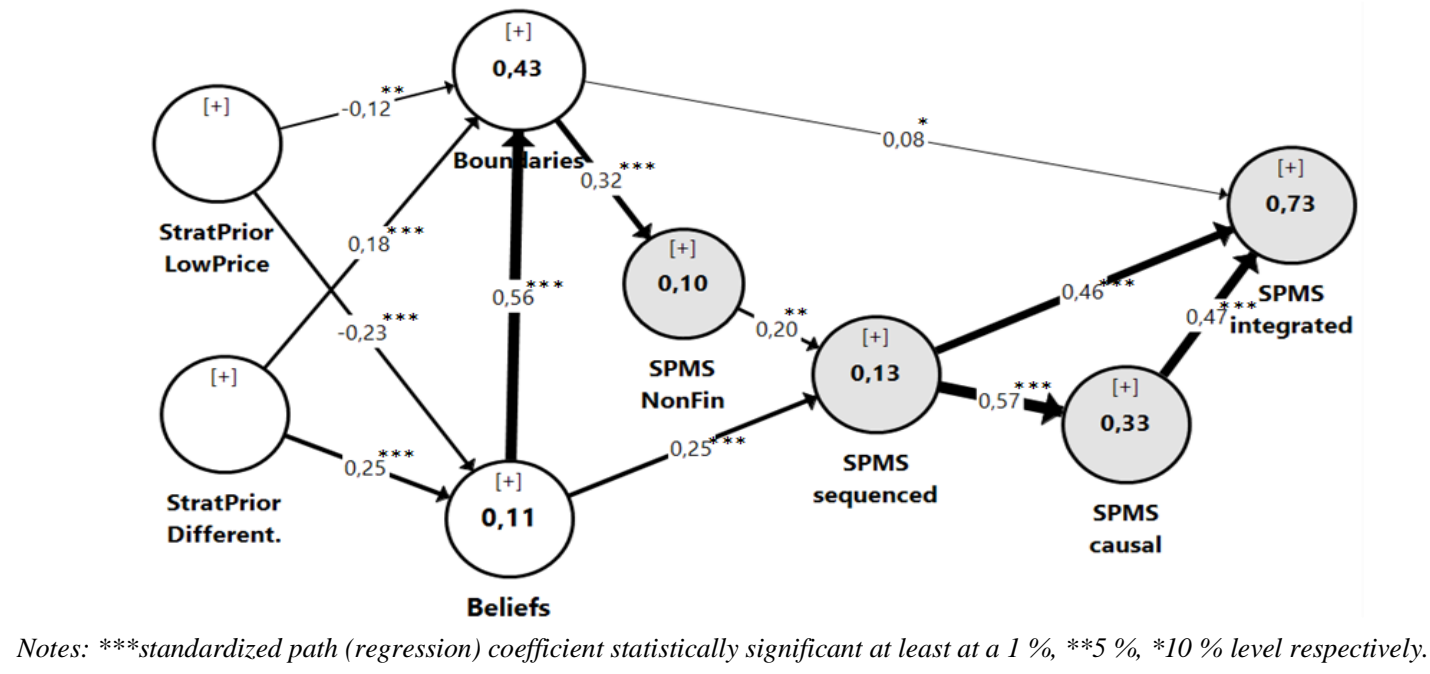

Figure 2. The Resulting Model

\section{Results}

The resulting model of linkages among all constructs is depicted in Figure 2. There are only the paths that were identified by bootstrapping as statistically significant at least at a 10 percent level. A line width emphasizes the strength of the relationship. The numbers in the circles represent the coefficients of determination $\mathrm{R}^{2}$ for the endogenous constructs whose names are written under the circle. The central analyzed concept of SPMS is in grey in Figure 2. Each grey circle stands for one of four distinctive features of SPMS identified above.

The regression coefficients by the paths from Strategic Priorities to Beliefs/Boundaries in Figure 2 show that hypothesis (H1) was not entirely verified. Firstly, no direct paths to the features of SPMS (in grey) were found to be statistically significant. That corresponds to the notion that the central concept of SPMS is just one component from the larger concept of MCS, next to beliefs and boundaries, two components which are more closely associated with strategic priorities. Secondly, negative standardized coefficients at strategic priorities of low prices mean that if the respondent's perception of low-price strategy increases by one standard deviation, the model predicts that this respondent will assess the use of belief systems in his company lower by 0.23 standard deviations and boundaries systems by 0.12 respectively. This finding is not consistent with $(\mathrm{H} 1)$ that companies with more polarized strategic choices would prefer correspondingly more polarized MCS tools and would not behave like companies "stuck in the middle" in Porter's words. Negative correlation coefficients between low-price strategic priority and beliefs/boundaries were found in the subsequent analysis of the control sample too $(-0.13$ for beliefs, -0.03 for boundaries) but these were due to their lower value and smaller sample size statistically insignificant.

Regarding the hypotheses (H4) and (H5), in general, these were found to be true. Indeed, companies reporting higher use of belief and boundary components of MCS reported higher features of SPMS as well. A detailed investigation of the linkages exposes ties (coefficient 0.32) between boundaries and non-financial features of SPMS, beliefs and sequenced feature of SPMS (coefficient 0.25), respectively. Similar path coefficients were found in control sample 0.42 and 0.25 respectively.

Finally, the impacts of industry (H2) and size (H3) on the resulting model were tested by PLS-MGA. This procedure found no statistically significant differences between coefficients of the resulting model calculated only with the data from appropriate subgroups (i.e. industrial $v$. trade/service, large v. medium sized respectively). That is why the null hypotheses about equality of means were retained and both hypotheses (H2) and (H3) were not verified. 


\section{Discussion}

Most relationships in the resulting model confirm the findings of the previous studies done by authors from developed countries. That is why the setting of the presented research in the Czech Republic is not of importance, the contingency factors seem to affect SPMS and MCS of the medium-sized and large companies domiciled in the CR similarly to situation abroad.

Despite the pronounced general agreement, more thorough detailed investigation of the resulting model in Figure 2 reveals very interesting paradox. The negative association between low-price strategic priorities and both MCS levers of control (beliefs and boundaries), which looks very controversial. One possible explanation is offered Siska (2014), who found that the majority of Czech managers perceived the strategy of their companies to be differentiation, even though the published financial data produced evidence about the prevalence of the cost leadership strategy. This manifestation of a single informant bias might be the reason why low-price strategic priority was reported by respondents to be low although they scored high in other questions. However, main reason of the paradoxically negative path coefficients lies in the mixed structure of the sample where subgroup of cost-leaders (43 organizations reporting aboveaverage low-price priority) and subgroup of differentiators (62 respondents) are together and next to the ambivalent rest. Thus, the separate estimates of the resulting model for the cost-leaders' subgroup produces the coefficient 0.01 for the path from Low-price strategy to Beliefs and 0.09 to Boundaries respectively. Contrary to that, in the subgroup of differentiators the same path coefficients were equal to negative -0.20 and -0.07 respectively because differentiators score low in low-price strategic priority and high in Beliefs and Boundaries. Due to higher count of differentiators than cost-leaders, their preferences outweighed the total estimate of the path coefficient into negative values. Similar "secret" could be behind the very low values of correlation coefficients -0.02 between "Strategy low cost" and "Belief systems" and 0.05 between "Strategy low cost" and "Boundary systems", which are reported by Bedford \& Malmi (2015). In summary, the detailed analysis proves that belief and boundary components of MCS are not very important tools for achieving cost-leadership. For that strategy, more financially focused tools from "Cost MCS" should be applied as identified by e.g. Sandino (2007).

The relation between MCS tools (beliefs and boundaries) and features of SPMS deserve more attention as well. Firstly, there is a medium association of boundaries with the use of non-financial indicators in SPMS and a very small association of boundaries with the integrated feature of SPMS (this was not confirmed by statistically insignificant path coefficient 0.04 in the control sample). In other words, it seems that companies which set more boundaries are more likely to set them using non-financial metrics. Secondly, in the case of belief systems, a small association with the sequenced feature of SPMS was detected. That feature is highly associated with causal links too. The possible explanation is that companies with stronger promotion of beliefs are more likely to have some comprehensive theories about their value creation and model these theories as a chain of causes and effects in their SPMSs. Thirdly, the lack of a direct link between beliefs and causal feature of SPMS in Figure 2 could be explained by the experience of Tuomela (2005) that in contrast to scholar literature, recommending determination of cause-and-effect relationships before implementing new measures, he found that the measures themselves would be used over time to confirm or reject alleged relationships.

Finally, the split of the central concept of SPMS into four distinctive features made it possible to model relations among them. The thick paths connecting grey circles in Figure 2 demonstrate quite high associations among all features. Although the direction of the arrows may be found arbitrary, the depicted statistically significant linkages indicate that data allow to model the following relations: companies using many non-financial indicators are more likely to tie strategic objectives through a sequence of measures and target values to action plans. This, in turn, mirrors in higher inclusion of cause-effect relations into SPMS measures. Eventually, sequenced chains of objectivesmeasures-actions and cause-effect relations among objectives and measures result in highly integrated SPMS.

The integrated feature of SPMS was identified as the ultimate endogenous construct in the resulting model (Figure 2) and can be viewed as a key target construct in the presented analysis. For this construct, the Importance-performance matrix analysis (IPMA) was done and the resulting matrix is depicted in Figure 3. It was calculated using PLS-SEM estimates of the path model and adding an additional dimension to the analysis that measures the average values of latent variables as percentages from the maximum point of the scale. "IPMA contrasts the structural model total effects (importance) and the average values of the latent variable scores (performance) to highlight significant areas for the improvement of management activities (or the specific focus of the model)." (Hair et al., 2014, p. 206).

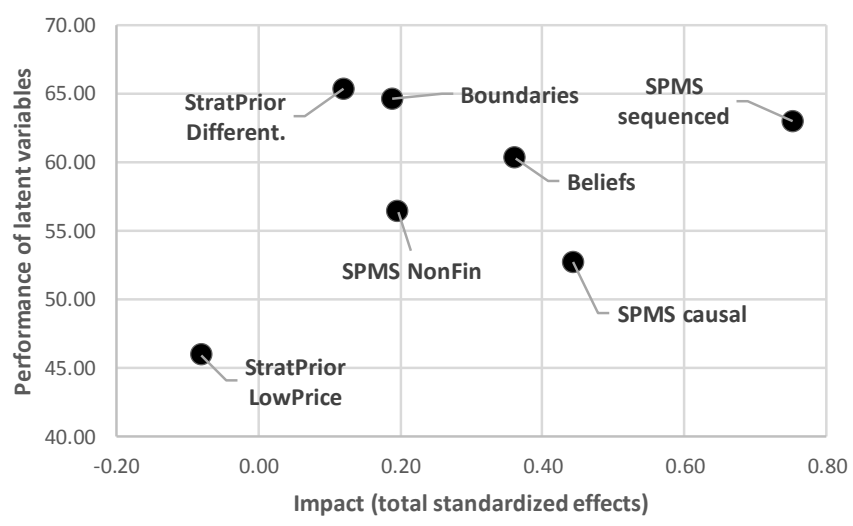

Figure 3. The Impact-Performance Matrix for SPMS Integrated Construct

\section{Conclusions}

To answer the title question, the central analyzed concept of SPMS was described through four distinctive features: (1) inclusion of non-financial metrics, (2) sequence of goalsmetrics-targets-action plans, (3) cause-effect linkages, (4) integration of long-term view. Each feature of SPMS was modeled by one latent construct. In the same PLS-SEM model, SPMS was found to be one component of the broader MCS. Belief and Boundary controls from Simons' influential MCS framework "Levers of Control" were the other 
components added to the MCS. The resulting MCS concept was tested whether or not it is impacted by the most dominant contingency factor of strategy, which was operationalized in two constructs: differentiation strategic priority and low-price strategic priority in accordance with M. E. Porter's categorization. Size and sector were the second and the third analyzed contingency factors but they did not seem to have any statistically significant impact .

The resulting PLS-SEM model gave answer to the title question in case of differentiation strategy. The significant paths revealed that Boundaries and Beliefs, not SPMSs themselves, are impacted by differentiation strategic priority in the first place. Assessment of low-price strategic priority impact required a more detailed analysis of the answers from companies where the low-price strategy is in use. This separate analysis demonstrated that belief and boundary components of MCS are not very important tools for achieving cost-leadership.

As far as managerial implications are concerned, applied IPMA shows that sequencing and causal links in SPMS have quite a high impact on SPMS ultimate integration. At the same time, IPMA warns that setting belief controls is more important for achieving integrated SPMS than setting boundaries. In contrast to that, average responses from the survey reveal that managers seem to be more successful in setting boundaries than beliefs. Therefore, formulation and promoting of core values and other belief controls is an issue to be solved by them. Causal modeling is the second major area of potential improvement that should be addressed by managers at least subsequently, i.e. after the implementation of new measures in SPMS.

There are a number of limitations to this study. Firstly, despite the refusal of non-response bias and of commonmethod bias, the generalization of findings is limited by the structure of the sample. Large companies were overrepresented and medium-sized underrepresented in the research sample. Secondly, the extent of analyzed contingency factors of SPMS was limited to strategy and MCS context only without taking into account e.g external environment, management style etc. In this respect, Gimzauskiene and Kloviene (2011) report weak, but statistically significant correlations between strategy and external environment (0.225) Thirdly, the applied PLSSEM assumes linearity and that is why it is incapable of capturing any curvilinear relationships. Fourthly, the chosen single informant approach could lead to biased results as well but triangulation in form of more respondents from one responding firm would have been prohibitively costly and time consuming. Finally, the presented study presumes that strategic priorities predetermine the design and use of SPMS. The future research should also address the inverted relation when information gathered through SPMS leads to the changes in strategy.

\section{Acknowledgement}

This paper was co-financed by internal funds of Faculty of Economics and Administration, Grant Agency of Masaryk University (MUNI/A/1001/2016) and IGA VSE Prague (F1/13/2015).

\section{References}

Bedford, D. S., \& Malmi, T. (2015). Configurations of control: An exploratory analysis. Management Accounting Research, 27, 2-26. https://doi.org/10.1016/j.mar.2015.04.002

Bedford, D. S., Malmi, T., \& Sandelin, M. (2016). Management control effectiveness and strategy: An empirical analysis of packages and systems. Accounting, Organizations and Society, 51, 12-28. https://doi.org/10.1016/j.aos.2016.04.002

Bhimani, A., \& Langfield-Smith, K. (2007). Structure, formality and the importance of financial and non-financial information in strategy development and implementation. Management Accounting Research, 18(1), 3-31. https://doi.org/10.10 16/j.mar.2006.06.005

Bisbe, J., \& Malagueño, R. (2012). Using strategic performance measurement systems for strategy formulation: Does it work in dynamic environments? Management Accounting Research, 23(4), 296-311. https://doi.org/10.1016/j.mar.2012.05.002

Cadez, S., \& Guilding, C. (2008). An exploratory investigation of an integrated contingency model of strategic management accounting. Accounting, Organizations and Society, 33(7-8), 836-863. https://doi.org/10.1016/j.aos.2008.01.003

Cadez, S., \& Guilding, C. (2012). Strategy, strategic management accounting and performance: a configurational analysis. Industrial Management \& Data Systems, 112(3), 484-501. https://doi.org/10.1108/02635571211210086

Chenhall, R. H. (2003). Management control systems design within its organizational context: Findings from contingency-based research and directions for the future. Accounting, Organizations and Society, 28(2-3), 127-168. https://doi.org/10.1016 /S0361-3682(01)00027-7

Chenhall, R. H. (2005). Integrative strategic performance measurement systems, strategic alignment of manufacturing, learning and strategic outcomes: an exploratory study. Accounting, Organizations and Society, 30(5), $395-422$. https://doi.org/10.1016/j.aos.2004.08.001

Chenhall, R. H. (2006). Theorizing Contingencies in Management Control Systems Research. Handbooks of Management Accounting Research, 1, 163-205. https://doi.org/10.1016/S1751-3243(06)01006-6

Davila, A., Foster, G., \& Jia, N. (2015). The Valuation of Management Control Systems in Start-Up Companies: International Field-Based Evidence. European Accounting Review, 24(2), 207-239. https://doi.org/10.1080/09638180.2014.965720 
De Vaus, D. A. (2002). Surveys in social research (5. ed). Crows Nest, NSW: Allen \& Unwin.

Eccles, R. G. (1991). The performance measurement manifesto. Harvard Business Review, 69(1), 131-137.

Epstein, M., \& Manzoni, J.-F. (1998). Implementing corporate strategy: From tableaux de bord to balanced scorecards. European Management Journal, 16(2), 190-203. https://doi.org/10.1016/S0263-2373(97)00087-X

Ferreira, A., \& Otley, D. (2009). The design and use of performance management systems: An extended framework for analysis. Management Accounting Research, 20(4), 263-282. https://doi.org/10.1016/j.mar.2009.07.003

Franco- Santos, M., Kennerley, M., Micheli, P., Martinez, V., Mason, S., Marr, B., ... Neely, A. (2007). Towards a definition of a business performance measurement system. International Journal of Operations \& Production Management, 27(8), 784801. https://doi.org/10.1108/01443570710763778

Franco-Santos, M., Lucianetti, L., \& Bourne, M. (2012). Contemporary performance measurement systems: A review of their consequences and a framework for research. Management Accounting Research, 23(2), 79-119. https://doi.org/10.1016/j. mar.2012.04.001

Garengo, P., \& Bititci, U. (2007). Towards a contingency approach to performance measurement: an empirical study in Scottish SMEs. International Journal of Operations \& Production Management, 27(8), 802-825. https://doi.org/10.1108/ 01443570710763787

Gimbert, X., Bisbe, J., \& Mendoza, X. (2010). The Role of Performance Measurement Systems in Strategy Formulation Processes. Long Range Planning, 43(4), 477-497. https://doi.org/10.1016/j.lrp.2010.01.001

Gimzauskiene, E., \& Kloviene, L. (2011). Performance Measurement System: Towards an Institutional Theory. Engineering Economics, 22(4). https://doi.org/10.5755/j01.ee.22.4.709

Grafton, J., Lillis, A. M., \& Widener, S. K. (2010). The role of performance measurement and evaluation in building organizational capabilities and performance. Accounting, Organizations and Society, 35(7), 689-706. https://doi.org/10.1016/j. aos.2010.07.004

Guilding, C., Cravens, K. S., \& Tayles, M. (2000). An international comparison of strategic management accounting practices. Management Accounting Research, 11(1), 113-135. https://doi.org/10.1006/mare.1999.0120

Hair, J. F., Hult, G. T. M., Ringle, C. M., \& Sarsted, M. (2014). A primer on partial least squares structural equations modeling (PLS-SEM). Los Angeles: SAGE.

Henri, J.-F. (2006a). Management control systems and strategy: A resource-based perspective. Accounting, Organizations and Society, 31(6), 529-558. https://doi.org/10.1016/j.aos.2005.07.001

Henri, J.-F. (2006b). Organizational culture and performance measurement systems. Accounting, Organizations and Society, 31(1), 77-103. https://doi.org/10.1016/j.aos.2004.10.003

Ittner, C. D., \& Larcker, D. F. (1998). Are nonfinancial measures leading indicators of financial performance? An analysis of customer satisfaction. Journal of Accounting Research, 36(SUPPL.), 1-35. https://doi.org/10.2307/2491304

Ittner, C. D., \& Larcker, D. F. (2003). Coming up Short on Nonfinancial Performance Measurement. Harvard Business Review, $81(11), 88-95+139$.

Kaplan, R. S., \& Norton, D. P. (1992). The balanced scorecard-measures that drive performance. Harvard Business Review, 70(1), 71-79.

Kaplan, R. S., \& Norton, D. P. (1996). The balanced scorecard: translating strategy into action. Boston, Mass: Harvard Business School Press.

Kaplan, R. S., \& Norton, D. P. (2004). Strategy maps: converting intangible assets into tangible outcomes. Boston: Harvard Business School Press.

Kaplan, R. S., \& Norton, D. P. (2008). The execution premium: linking strategy to operations for competitive advantage. Boston, Mass: Harvard Business Press.

Koufteros, X., Verghese, A. (John), \& Lucianetti, L. (2014). The effect of performance measurement systems on firm performance: A cross-sectional and a longitudinal study. Journal of Operations Management, 32(6), 313-336. https://doi.org/10.1016/j. jom.2014.06.003

Langfield-Smith, K. (2006). A Review of Quantitative Research in Management Control Systems and Strategy. Handbooks of Management Accounting Research, 2, 753-783. https://doi.org/10.1016/S1751-3243(06)02012-8

Langfield- Smith, K. (2008). Strategic management accounting: how far have we come in 25 years? Accounting, Auditing \& Accountability Journal, 21(2), 204-228. https://doi.org/10.1108/09513570810854400

Lee, L., Petter, S., Fayard, D., \& Robinson, S. (2011). On the use of partial least squares path modeling in accounting research. International Journal of Accounting Information Systems, 12(4), 305-328. https://doi.org/10.1016/j.accinf.2011.05.002

Magretta, J. (2013). Understanding Michael Porter: The Essential Guide to Competition and Strategy. Harvard Business Press.

Malmi, T., \& Brown, D. A. (2008). Management control systems as a package-Opportunities, challenges and research directions. Management Accounting Research, 19(4), 287-300. https://doi.org/10.1016/j.mar.2008.09.003

Melnyk, S. A., Bititci, U., Platts, K., Tobias, J., \& Andersen, B. (2014). Is performance measurement and management fit for the future? Management Accounting Research, 25(2), 173-186. https://doi.org/10.1016/j.mar.2013.07.007 
Melnyk, S. A., Stewart, D. M., \& Swink, M. (2004). Metrics and performance measurement in operations management: Dealing with the metrics maze. Journal of Operations Management, 22(3), 209-217. https://doi.org/10.1016/j.jom.2004.01.004

Merchant, K. A., \& Otley, D. T. (2006). A Review of the Literature on Control and Accountability. Handbooks of Management Accounting Research, 2, 785-802. https://doi.org/10.1016/S1751-3243(06)02013-X

Neely, A., Gregory, M., \& Platts, K. (1995). Performance measurement system design: A literature review and research agenda. International Journal of Operations and Production Management, 15(4), 80-116. https://doi.org/10.1108/0144 3579510083622

Neely, A., Mills, J., Platts, K., Richards, H., Gregory, M., Bourne, M., \& Kennerley, M. (2000). Performance measurement system design: Developing and testing a process-based approach. International Journal of Operations and Production Management, 20(10), 1119-1145. https://doi.org/10.1108/01443570010343708

Nixon, B., \& Burns, J. (2012). The paradox of strategic management accounting. Management Accounting Research, 23(4), 229244. https://doi.org/10.1016/j.mar.2012.09.004

Otley, D. (2016). The contingency theory of management accounting and control: 1980-2014. Management Accounting Research, 31, 45-62. https://doi.org/10.1016/j.mar.2016.02.001

Paladi, I., \& Fenies, P. (2016). Performance management in central and eastern european countries: A literature review. Studies in Managerial and Financial Accounting, 31, 215-271. https://doi.org/10.1108/S1479-351220160000031008

Pavlatos, O., \& Kostakis, H. (2015). Management accounting practices before and during economic crisis: Evidence from Greece. Advances in Accounting, 31(1), 150-164. https://doi.org/10.1016/j.adiac.2015.03.016

Porter, M. E. (1980). Competitive Strategy: Techniques for Analyzing Industries and Companies. Free Press. Retrieved from http://scholar.google.com/scholar?cluster=14390277095902442371\&hl=en\&oi=scholarr

Rigdon, E. E. (2012). Rethinking Partial Least Squares Path Modeling: In Praise of Simple Methods. Long Range Planning, 45(56), 341-358. https://doi.org/10.1016/j.lrp.2012.09.010

Ringle, C. M., Wende, S., \& Becker, J.-M. (2015). SmartPLS 3. SmartPLS GmbH. Retrieved from http://www.smartpls.com

Ross, L., \& Kovachev, I. (2009). Management accounting tools for today and tomorrow. Chartered Institute of Management Accountants, November, 1-32.

Sandino, T., 2007. Introducing the first management control systems: Evidence from the retail sector. Accounting Review 82, 265293. https://doi.org/10.2308/accr.2007.82.1.265

Sarstedt, M., Henseler, J., \& Ringle, C. M. (2011). Multigroup Analysis in Partial Least Squares (PLS) Path Modeling: Alternative Methods and Empirical Results. In M. Sarstedt, M. Schwaiger, \& C. R. Taylor (Eds.), Advances in International Marketing (Vol. 22, pp. 195-218). Emerald Group Publishing Limited. Retrieved from http://www.emeraldinsight.com/doi/10.1108/S $1474-7979 \% 282011 \% 290000022012$

Simons. (1995). Levers of Control. McGraw-Hill Companies.

Simons, R. (2010). Stress-test your strategy: The 7 questions to ask. Harvard Business Review, 88(11).

Siska, L. (2014). Perceived versus financially measured strategic position of a company. Change Management, 13(3), 11-21. https://doi.org/10.18848/2327-798X/CGP/v13i03/59249

Siska, L. (2016). The contingency factors affecting management accounting in Czech companies. Acta Universitatis Agriculturae et Silviculturae Mendelianae Brunensis, 64(4), 1383-1392. https://doi.org/10.11118/actaun201664041383

Smith, D., \& Langfield-Smith, K. (2004). Structural Equation Modeling in Management Accounting Research: Critical Analysis and Opportunities. Journal of Accounting Literature, 23, 49.

Speckbacher, G., Bischof, J., \& Pfeiffer, T. (2003). A descriptive analysis on the implementation of Balanced Scorecards in German-speaking countries. Management Accounting Research, 14(4), 361-388. https://doi.org/10.1016/j.mar.2003.10.001

Strauß, E., \& Zecher, C. (2013). Management control systems: a review. Journal of Management Control, 23(4), $233-268$. https://doi.org/10.1007/s00187-012-0158-7

Taylor, A., \& Taylor, M. (2014). Factors influencing effective implementation of performance measurement systems in small and medium-sized enterprises and large firms: a perspective from Contingency Theory. International Journal of Production Research, 52(3), 847-866. https://doi.org/10.1080/00207543.2013.842023

Tessier, S., \& Otley, D. (2012). A conceptual development of Simons' Levers of Control framework. Management Accounting Research, 23(3), 171-185. https://doi.org/10.1016/j.mar.2012.04.003

Tuomela, T.-S. (2005). The interplay of different levers of control: A case study of introducing a new performance measurement system. Management Accounting Research, 16(3), 293-320. https://doi.org/10.1016/j.mar.2005.06.003

Widener, S. K. (2007). An empirical analysis of the levers of control framework. Accounting, Organizations and Society, 32(7-8), 757-788. https://doi.org/10.1016/j.aos.2007.01.001

The article has been reviewed.

Received in January 2017; accepted in November, 2018. 